Lexical Acquisition in Elementary Science Classes 1

\title{
Lexical Acquisition in Elementary Science Classes
}

Date of submission: September ${ }^{2 n d}, 2005$

Date of resubmission: March 13th, 2006 
Lexical Acquisition in Elementary Science Classes 2

\section{Abstract}

The purpose of the research is to further our understanding of lexical acquisition in the beginning primary school child by investigating word learning in small-group elementary science classes. Two experiments were conducted to examine of the role of semantic scaffolding (e.g., use of synonymous terms) and physical scaffolding (e.g., pointing to referents) in children's acquisition of novel property terms. Children's lexical knowledge was assessed using multiple tasks (naming, comprehension and definitional). Children struggled to acquire meanings of adjectives without semantic or physical scaffolding (Experiment 1), but were successful in acquiring extensive lexical knowledge when offered semantic scaffolding (Experiment 2). Experiment 2 also showed that semantic scaffolding used in combination with physical scaffolding helped children acquire novel adjectives and children who correctly named pictures of adjectives had acquired definitions. 
Lexical Acquisition in Elementary Science Classes 3

Children's acquisition of word meanings in the classroom

School entry provides children with many opportunities to acquire new words (Graves,

1986; Baunmann \& Kame'enui, 1991); word learning is associated with academic success

(Chall, Jacobs, \& Baldwin, 1990; Baumann, Kame'enui, \& Ash, 2003). There is converging evidence to show that teachers play a critical role in helping children acquire new words by offering important information about word meanings, such as verbal explanations (e.g., Biemiller, 2004; McKeown \& Beck, 2004; Graves, 2006). However, previous research with primary grade children has focused almost exclusively on direct vocabulary instruction during episodes of story reading in narrative contexts (Elley, 1989; Brabham \& Lynch-Brown, 2002; Biemiller \& Boote, in press). There appears to be little information about the ways in which teachers help children acquire new words using expository methods or during episodes of content-area teaching (Carlisle, Fleming, \& Gudbransden, 2000; Carey, 1986). Expository methods of teaching used in subjects, such as science have important implications for lexical acquisition with respect to the lexical items children encounter and the methods of scaffolding provided by teachers across the curriculum (Carlisle et al,, 2000). To broaden our understanding of classroom-based word learning, the present study investigated the ways in which teacher scaffolding helps children acquire new words in science classes (conducted with four to six year old children).

Our study examines the ways in which scaffolding provided by teachers during typical discussion-based activities supports word learning for adjectives. Two experiments were conducted to explore the importance of semantic scaffolding (e.g., use of synonymous terms) and physical scaffolding (e.g., making reference to visual stimuli). Experiment 1 was a baseline study designed to explore whether the children acquire novel words from context, with minimal scaffolding whereas Experiment 2 explored improvements in word learning success following the provision of explicit semantic scaffolding or a combination of direct semantic and physical 
Lexical Acquisition in Elementary Science Classes 4

scaffolding in context. In both experiments numerous measures of word knowledge were administered to assess the nature of understandings children acquired about word meanings.

Lexical acquisition and the primary grade child

The typical school child is estimated to acquire up to eight new words per day (Graves, 1986; Beck \& McKeown, 1991). Most new words are encountered incidentally rather than via direct vocabulary instruction (Penno, Wilkinson, \& Moore, 2002; Nagy \& Herman, 1987); oral contexts of word exposure play a critical role in helping children acquire new vocabulary both during incidental and instruction-based exposures (e.g., Biemiller, 2004; Clark \& Wong, 2002). Oral contexts of word exposure are important because the speaker (e.g., teacher) directs children's attention to relevant aspects of meaning using a range of verbal and non-verbal information. Evidence for the ways in which oral contexts scaffold word learning stem from two important lines of inquiry. Firstly, research conducted with pre-school children offers a valuable insight into the sources of information children use to acquire words from incidental exposures. Secondly, classroom studies illustrate the kinds of instruction that best facilitate word learning among primary grade children during episodes of story reading.

Pre-school studies

Research conducted with pre-school children (between the ages of two and four) typically builds on the notion of fast mapping (Carey, 1978) in which children are purported to acquire words with ease and rapidity from minimal exposures. Researchers have examined the ways in which children make quick mappings between words and referents from incidental encounters. There is converging evidence from laboratory studies to indicate that children draw on the information-rich context in which word learning occurs to fast map new words. By the end of the pre-school period, children have a range of cognitive, linguistic and social competencies in place to make use of a range of word-related information discussed below (Baldwin, 1991, Booth \& 
Lexical Acquisition in Elementary Science Classes 5

Waxman, 2002; Bowey, 1996; 2001; Clark \& Wong, 2002; de Jong, Sevele, \& van Veen, 2000; Hoff \& Naigles, 2002).

Pre-school children are sensitive to a range of linguistic information available in the discourse context (Deák, 2000a, 2000b; Goodman, McDonough, \& Brown, 1998). From age two children draw on syntactic structure to acquire information about word meanings (e.g., Naigles \& Hoff-Ginsberg, 1995; Gleitman, 1990; Dockrell \& McShane, 1990) using argument structures within sentences, particularly for verbs and adjectives. For example, Prasada's (1997) research with three-year old children indicated that modifiers (e.g., "the fep blicket") draw children's attention to categories whereas adjectives presented in the predicate position (e.g., "the blicket is fep") draw attention to properties.

While syntactic cues guide children's attention to relevant aspects of meaning, they do not offer specific information about what a word means. Syntactic cues can be insufficient to support word learning (Mintz \& Gleitman, 2001; Klibanoff and Waxman, 2000). However, research at the pre-school level indicates that the words and phrases that surround novel words often offer children a form of semantic scaffolding. For instance, novel words are sometimes embedded in sentences containing semantically-related terms. One may deduce that the term transparent means "see through" upon hearing transparent used in combination with a synonym, "It is transparent, it is see-through" (Clark, 1997; Clark \& Wong, 2000). Explicit information about word meanings has a profound effect on word learning, such that when exposed to explicit semantic information, children are more likely to acquire word meanings than children without this support (Ralli \& Dockrell, in press2005).

Children also acquire important information about word meanings from non-verbal cues During the course of communication, the speaker continually provides the child with non-verbal cues, such as pointing gestures (McNeil, 1992) that direct children's attention to word meanings. Speakers can provide "physical scaffolding" by invoking the physical context; they point to 
Lexical Acquisition in Elementary Science Classes 6

referents or manipulate objects. If a speaker points to an object when introducing a new word, the child infers that the word relates to the object referentially (Tomasello \& Akhtar, 1995).

While children in the pre-school period appear to acquire words with remarkable ease and rapidity using context cues, it is unclear how well research findings generalize to children of school age. A limitation with much pre-school research is that it is conducted in highly controlled, laboratory situations, or with a narrow range of word types, usually count nouns (Deák \& Wagner, 2003). As children progress through the school years they are exposed to a variety of lexical items, some of which are difficult to acquire (Nagy, Diakidoy, \& Anderson, 1993; Smiley \& Huttenlocher, 1995). In subject area classes like science, children encounter a high proportion of adjectives relating to phenomena observed during inquiry and experimentation (Soler, 2002). There is reason to suppose that adjectives present challenges for acquisition, especially in comparison to nouns.

Noun learning appears to be privileged as nouns typically map on to directly observable phenomena (Bornstein, Cote, Maital, Painter, Park, Pascual, Pêcheux, Ruel, Venuti, \& Vyt, 2004). Adjectives and verbs however are relational terms and thus present greater challenges for acquisition (Gillette, Gleitman, Gleitman, \& Lederer, 1999). Adjective meaning for example is interpreted in relation to the nouns with which they co-occur (see Waxman \& Klibanoff, 2000 for a discussion regarding adjective acquisition). While scholars have investigated children's acquisition of nouns and to some extent verbs, few have explored adjectives or the kinds of informational input needed to support adjective acquisition (Klibanoff \& Waxman, 2000). Thus, further investigation of children's acquisition of adjectives would serve to further our understanding of lexical acquisition. 
Lexical Acquisition in Elementary Science Classes 7

\section{Classroom studies}

There have been a number of educational studies focusing on word learning at the elementary level. Studies have explored incidental word learning, although most conducted with primary grade children in oral contexts focus on methods of direct vocabulary instruction. Studies have almost exclusively been conducted in story reading paradigms, in which a teacher reads aloud a narrative to children. The general consensus from the classroom, story-reading literature is that direct instruction is critical for fostering vocabulary acquisition. Evidence clearly shows that children acquire word meanings more successfully when directly taught than when encountered incidentally (Brabham \& Lynch-Brown, 2002; Penno et al, 2002; Brett,

Rothlein, \& Hurley, 1996; Elley, 1989). While incidental encounters can scaffold word learning (e.g., examples and restatements of word meanings), children sometimes struggle to figure out how to extrapolate word meanings from context cues (e.g., McKeown \& Beck, 2004). Further, children's ability to acquire word meanings from context depends critically on the directness of the cue and children's prior vocabulary (e.g., Beck, McKeown, \& McCaslin, 1983), such that words are acquired best when information is direct (e.g., words are defined) and children have larger vocabularies so they can understand the words and phrases surrounding novel terms.

While there is no single, optimal method of vocabulary instruction, educational reviews indicate that effective instruction ought to present multiple exposures, broad information about word meanings and engage students in deep processing of word meanings, such as discussion activities (Mezynski, 1983; Stahl \& Fairbanks, 1986). Indeed, empirical evidence indicates that children benefit from direct explanations by the teacher or discussions about meanings with the teacher (Brabham \& Lynch-Brown, 2002; Hargrave \& Senechal, 2000) and teaching contexts in which words are exposed on multiple occasions (Brabham \& Lynch-Brown, 2002; Brett et al, 1996; Elley, 1989). It is important to point out while the abovementioned methods are undoubtedly effective for fostering vocabulary acquisition there are limited opportunities for 
Lexical Acquisition in Elementary Science Classes 8

direct instruction and or multiple teachings of word meanings in classrooms (Nagy \& Herman, 1987; Penno et al, 2002). Thus, a comprehensive account of vocabulary acquisition among school children ought to consider methods of word exposure that support word learning, but at the same time are representative of typical word learning situations.

Observations of classroom exposures indicate that teachers seldom offer direct instruction about word meanings. However, they often find opportunities to offer semantic scaffolding. In science teaching situations, for example, teachers commonly draw links between semantically related terms during the course of teaching ("transparent means see-through") or contrasting word meanings ("It is opaque, not see-through") (Carlisle et al, 2000; Best, 2003). Further, the provision of semantic support is related to the lexical item. Best's (2003) observations of teachers' introductions to novel words in science classes indicated that semantic support is used most often during exposure to adjectives, which as indicated earlier play a critical role in science instruction (Soler, 2002).

Scholars agree that situations in which teachers offer semantic information, such as brief definitions or synonyms, help children acquire word meanings (Graves, 2000; Graves, Juel, \& Graves, 2004). Research with kindergarten children through to grade two children demonstrates that explicit semantic input is effective in facilitating word learning (e.g., Senechal, 1997; Brett et al, 1996; Elley, 1989). However, classroom studies have shown that Educational research alse indieates that children's ability to utilize semantic information depends on their vocabulary size, $\underline{\text { such that children with larger vocabularies are more likely to utilize semantic input to acquire }}$ word meanings than children with smaller vocabularies (e.g., Robbins \& Ehri, 1994; Penno et al, 2002). While there is abundant evidence for the role of semantic support in classroem based word learning, there is little information available about whether semantic support is optimal for particular types of word, such as adjectives or verbs. 
Lexical Acquisition in Elementary Science Classes 9

Finally, as with the pre-school literature, the educational literature also indicates that physical scaffolding as well as verbal scaffolding supports word learning. A number of studies assessing the role of brief explanations in word learning indicate that making reference to text pictures during story reading supports word learning. However, it appears that a combination of reference to text pictures and verbal explanations were more successful than the use of text pictures in isolation (Senechal, Thomas, \& Monker, 1995; Senechal, 1997). Thus, it appears that physical scaffolding may bolster linguistic scaffolding by providing additional information about word meanings, such as information about word reference. Despite the potential importance of physical scaffolding, few classroom-based studies of lexical acquisition have considered this dimension. Yet, the study of physical scaffolding is likely to be critical in content area teaching (French \& Peterson, 2005).Teachers continuously refer to posters, diagrams and experimental equipment to teach science concepts and processes (Lemke, 1990; Carlisle et al, 2000). When making use of referential materials teachers use words that relate to visual referents (e.g., observable properties) and draw attention to relevant aspects of word meanings (e.g., properties) by pointing to or manipulating objects (Best, 2003). Importantly, research in science education indicates that instances of teaching in which the teacher demonstrates or emphasizes concepts non-verbally are effective for fostering understanding of science concepts (e.g., O’Toole, 1999; Ogborn, Kress, Martins, \& McGillicuddy, 1996; Lloyd \& Contreras, 1987).

In conclusion, research studies about lexical acquisition reflect two different orientations, namely, ways in which (preschool) children acquire words and the contexts that support word learning. The fast mapping literature emphasizes the ways in which children acquire word meanings from context, however, it may not explain lexical acquisition in real world settings, such as the classroom. Scholars have argued that the investigation of word learning in naturalistic contexts helps us expand our understanding of the kinds of input that drive lexical acquisition (Nelson, 1988; 1990; L. Bloom, 1997). In contrast the majority of research studies 
Lexical Acquisition in Elementary Science Classes 10

conducted in classroom settings with primary grade children has focused on a limited range of exposures (i.e., methods of direct teaching) in story reading settings. Studies that merge these two comcomplementaryplimentary approaches can extend our knowledge of the acquisition process.

\section{Children's understandings of word meanings}

Thus far, the discussion has focused on the role of scaffolding in children's acquisition of word meanings. This section addresses the nature of children's lexical representations with a view to identifying the ways in which differential levels of scaffolding support understandings of word meanings. Much of the fast mapping literature purports that brief, incidental exposures support the acquisition of 'initial' understandings, which are typically unstable, partial and fragmentary (Deák \& Wagner, 2003). However, educational studies indicate that direct instruction supports deeper understandings of word meanings, such as definitional knowledge (e.g., Biemiller \& Boote, in press; Penno et al, 2002).

There are no formal criteria to judge when a word is known (Beck \& McKeown, 1991). However, when a child acquires a new word, they must identify the sound in the speech stream to encode a phonological representation and then establish a mapping between the word and referent. Children also acquire more detailed semantic representations, such as definitional knowledge (Dockrell \& Messer, 2004). The nature of lexical knowledge acquired (e.g. production or comprehension) offers an important insight into how well a word is known (Best, 2003; McGregor, Friedman, Reilly, \& Newman, 2002; Ralli, 1999). Whereas word recognition knowledge represents initial lexical knowledge (Oviatt, 1980), definitional knowledge is indicative of the child having acquired deeper semantic knowledge (e.g., Ralli, 1999). Recent research suggests that accurate naming, or production is also indicative of the child having acquired semantic knowledge (McGregor, et al, 2002; Best et al, 2006). McGregor and colleagues (2002), in an investigation of 5- and 7-year-olds children's semantic representations 
Lexical Acquisition in Elementary Science Classes 11

of object terms, established that accurate naming is related to the acquisition of semantic knowledge; children who accurately named objects were also likely to have in place accurate semantic knowledge measured in terms of the production of word definitions. McGregor's findings suggest that semantic knowledge may be an important prerequisite for the accurate production of a lexical item.

Thus, to establish what has been acquired, it is important to assess lexical knowledge with a range of word knowledge assessments (Beck \& McKeown, 1991). These measures should include both production and comprehension, moving beyond the conventional forced-choice multiple-choice comprehension task (Anglin, 1993). However, many studies of word learning, especially at the pre-school level, administer single measures of assessment, invariably the multiple-choice comprehension task. The multiple-choice task is an assessment of receptive vocabulary knowledge, which requires the child to select a correct response from a set of distractors. It is a flat measure that offers no indication about how well a word is known (Ralli \& Dockrell, in press2005). While some classroom studies have assessed the depth of children's knowledge, they have typically used a narrow range of tasks, usually definitional tasks (Curtis, 1987).

It is important that methods of semantic assessment extend beyond definitional tests. Firstly, as indicated above, accurate naming is critically related to knowing a word and the child having acquired semantic knowledge. Naming may also be a common method of assessment used by teachers to assess whether a word is known. Secondly, while definition assessments are useful they can present difficulties for completion because children encounter difficulty explaining and describing (Rennie \& Jarvis, 1995). Recent research has shown that creative tasks, such as drawing are effective alternatives for eliciting semantic knowledge among schoolage children (McGregor et al, 2002; Best et al., 2006). Drawing assessments are commonly used educational tools for eliciting semantic knowledge (Driver, Squires, Rushworth, \& Wood- 
Lexical Acquisition in Elementary Science Classes 12

Robinson, 1994; Dove, Everett, \& Preece, 1999). Further, drawing tasks can be more successful than traditional verbal tasks for assessing knowledge and eliciting information children find difficult to explain (Gross \& Teubal, 2001).

The current research

The study reported here builds on existing research regarding the role of semantic and physical scaffolding in lexical acquisition. In line with previous research, the purpose was to examine vocabulary acquisition following exposure to different kinds of scaffolding.s with differing levels of seaffelding. However, our research expanded on previous work by focusing on children's acquisition of adjectives in an expository, science-teaching context. We investigated the kinds of informational support (semantic and physical scaffolding) that supports adjective acquisition typically encountered in science classes. Further, our study investigated the nature of knowledge children acquired from typical classroom exposures (naming, comprehension and semantic knowledge). Two experiments were conducted. Experiment 1 was a baseline study designed to explore whether the children acquire novel adjectives from the discourse context and whether different linguistic exposures (syntactic frames) play a role in children's adjective acquisition. Experiment 2 explored the ways in which more direct semantic and physical scaffolding support children's acquisition of novel adjectives.

Both experiments were carried out in a naturalistic science context of small-group lessons. In line with typical classroom exposures, in which there is a high level of group work (Blatchford \& Kutnick, 2004):- Tthe experiments were conducted with groups of five children, and the- The experimenter (a Graduate Student in Psychology) played the role of a teacher. She introduced novel words when showing children visual materials to explain science-related concepts and phenomena. The extent of lexical knowledge acquired was assessed using multiple measures of word-knowledge assessment. Effects of word learning and levels of comprehension were assessed using a multiple-choice comprehension task one week before the science lessons 
Lexical Acquisition in Elementary Science Classes 13

(baseline) and immediately after the science lessons (post-test). At post-test, the extensiveness of children's word knowledge assessed using picture-naming, definition and drawing tasks.

Experiment 1 also incorporated an adjective generalization task, which assessed whether children mapped novel adjectives to properties or categories.

\section{Experiment 1}

Experiment 1, the baseline assessment, compared children's acquisition of novel adjectives introduced in differing syntactic frames; syntax in which adjectives modify nouns ("this is a coarse leaf") and syntax in which adjectives are used in the predicate position ("this leaf is coarse"). The decision to explore adjective syntax was twofold. Firstly, the manipulation of adjective syntax allowed us to test Prasada's (1997) hypothesis, cited in the introductory section about the role of adjective syntax in word learning with a sample of school-age children in a real world context. Prasada's hypothesis purports that adjectives used as modifiers draw attention to categories whereas adjectives used in the predicate position draw attention to properties. Prior observational work in elementary science classrooms indicated teachers are more likely to introduce novel adjectives as modifiers (e.g., "the transparent vase") (Best, 2003). Secondly, the differential emphasis of the input would predict that children's new representations would differ in nature and detail. Exploring children's acquisition of novel adjectives using syntax cues provided an opportunity to determine the rate of learning and extent of understandings acquired when hearing words in the discourse context, with minimal scaffolding in typical classroom interactions.

\section{Method}

\section{Participants}

Eighty children with English as their first language were drawn from science classes in three elementary schools based in a suburban area of Southeast England. Children were drawn from Year 1 classes, which comprise four to six-year old children (children would be classified 


\section{Lexical Acquisition in Elementary Science Classes 14}

as either kindergarten or Grade 1 level in the United States). Participant's ranged in age from $4 ; 4$ to $6 ; 3$ years $(M=5 ; 4, S D=0.37)$; forty were female and forty were male. 
Lexical Acquisition in Elementary Science Classes 15

\section{Design}

To assess effects of word learning, children's knowledge of four adjectives exposed in the science lessons (exposure adjectives) was compared to two novel adjectives not introduced in the science lessons (control adjectives). Thus, the within-subjects variable was word type (exposure or control). To investigate the effect of modification and predication syntax in adjective acquisition there was the between-subjects variable of adjective syntax used during word exposure (modification or predication).

\section{Materials}

Novel adjectives. The four exposure adjectives and two control adjectives are reported in Table 1. Target adjectives needed to be a) real words to avoid the limitations of using nonsense items b) unknown to the children, c) apply to the relevant curricular domain and d) related to observable properties (e.g., colouring, texture and markings). There were a limited number of items that met all these criteria. The exposure and control adjectives are displayed in Table 1.

To ensure words related to concepts taught in National Curriculum for England and Wales (Department for Education and Employment, 1999), key terms, such as "translucent" were selected using a combination of teaching guidance resources and educational books for children in Key Stage 1 (5 -7 year old children). The words were to be non-inflected to avoid conflating effects of learning with morphological information.

Because particular categories may draw attention to properties more effectively than others, novel properties were depicted on entities relating to two domains specified in the National Curriculum for England and Wales. It was important to use familiar science domains that are appropriate for the primary grades investigated and thus we selected words that mapped onto both plants and geographical features (e.g., mountains and rivers). Each novel adjective was depicted on either entity set A (plants) or entity set B (geographical features). In order to control for the type of entity on which properties were depicted, half of the participants encountered 
Lexical Acquisition in Elementary Science Classes 16

entity set A whereas the remaining half encountered entity set B (see Table 1). Balancing for item exposure meant that some terms were used in unconventional ways. We ensured that there were no semantic incompatibilities between the domain and novel adjectives so that successful acquisition of the meaning of the novel adjectives would not lead the child to view the exposure domain as inappropriate.

To ensure words were novel to children, we used a procedure already established as being successful in identifying novel words, based on selecting very low frequency terms that are unlikely to be known to primary-grade children (Dockrell, Messer and George, 2001). Word frequency was assessed using a range of corpora that assess the frequency with which particular terms occur within in spoken and written language. We used the Thorndike and Lorge Teacher's Word Book of 30,000 words (Thorndike and Lorge, 1949), Kucera and Francis's Computational Analysis of Present Day American English (Kucera \& Francis, 1967), Brown’s Frequency count of 190,000 words in the London-Lund Corpus of English Conversation (Brown, 1984) and Burroughs study of vocabulary of young children (Burroughs, 1957).

\section{INSERT TABLE 1 ABOUT HERE}

Word exposure materials. The novel adjectives were introduced in the context of a science lesson. Small groups of children were pulled aside to take part in a lesson -in which the teacher focused on "things that are alive and growing". The lesson followed a script (see Appendix), which was based on a question-answer session between the experimenter and groups of five children. To introduce the words, the experimenter showed children four color posters of countryside scenes (gardens featuring flowers, or mountainous scenes with trees, rocks and rivers) to elicit knowledge of things that are alive and growing. Two different sets of posters were used; one set contained pictures of target properties represented on plants (entity set A) whereas the other set contained pictures of target properties represented on geographical features (entity set B). 
Lexical Acquisition in Elementary Science Classes 17

Knowledge assessment tests. At baseline children completed two tasks. Firstly, they completed the British Picture Vocabulary Scale II (BPVS II) (Dunn, Dunn, Whetton, \& Brurley, 1987), which is a standardized test used to assess receptive vocabulary size. The child is required to select a picture (from a choice of four) that relates to a word uttered by the experimenter.

Children respond to sets of 12 multiple-choice items, starting at the age appropriate item set (based on their age in years and months) and work through the sets until they make eight or more errors.

Secondly, participants completed a multiple-choice comprehension task specially developed for the present experiment to assess their knowledge of the exposure adjectives and control adjectives. Participants were to select a target picture displayed alongside three distractor items, which included the original object but not the property, and a "don't know" option, which was used to reduce the chances of guessing. The pictures, produced by artist, were colour illustrations showing four different attributes depicted on the entity on which the property was depicted in the science lesson (e.g., flower or tree). For each word assessed, there was a target picture (e.g., flower depicting target property) and three distrctors, which depicted properties relating to the other target words For example, for the term, piebald, the child was presented with the target picture, (e.g., flower with spotted petals) and pictures of flowers with different kinds of petals (e.g., green petals, pale petals and petals with a translucent appearance). Two versions of the multiple-choice task were developed to match the testing conditions to the word exposure conditions (see entity set A and B in Table 1), such that participants exposed to entity set A encountered pictures of plants whereas participants exposed to entity set B encountered pictures of geographical features.

At post-test, children completed four tasks developed for the purpose of the present study. Firstly, they completed the multiple-choice task used at baseline. Secondly, children completed a picture-naming task, which required participants to accurately name colour- 
Lexical Acquisition in Elementary Science Classes 18

illustrations of the target properties. Again, two versions of the task were developed so that the testing conditions corresponded to entity set A or entity set B. Responses to the naming task were classified in one of five categories, based on children's responses: 1) accurate naming (child produced exposures or control adjectives - piebald, coarse, luminous, verdant, pallid and translucent); 2) color terms (child names colours, such as "green" or "white" 3) Textures and markings (child names appearance of entities, such as "spotty" or "shiny"; 4) category response (child names a noun, such as "flower" rather than an adjective; and 5) no response (e.g., "don't know").

Thirdly, participants completed a drawing and definition task, which required children to depict the novel properties and define word meanings, respectively. Drawings were classified in one of four categories, based on student responses; 1) drawing of target property (child produced drawing of an entity, such as a flower, that depicted the target attributes, such as spotted effect for piebald); 2) drawings of entities observed in the science lessons (drawings of entities children observed in the science lessons, such as flowers and trees that did not depict target properties.

However, children sometimes depicted non-target properties on their drawings, such as colourful petals or leaves); 3) irrelevant drawings (drawings of entities children did not observe in the science lessons, such as people and houses; and 4) no response (“don't know'). Definitions were classified in one of four categories, based on children's responses: 1) accurate definition (child produced an appropriate description or synonym for the adjectives, such as "spotted: for piebald or "rough" of coarse); 2) incorrect definition of attribute (e.g., child produced incorrect description or adjective for the target terms, such as "green" for piebald, or "dark" for pallid); 3) object naming (child produced name of object seen in science lessons, such as flowers or trees); and 4) no response (“don’t know”).

Fourthly, participants completed an adjective generalization task designed to assess whether children were more likely to associate the adjectives with the target property (e.g., 
Lexical Acquisition in Elementary Science Classes 19

spotted appearance for piebald) or the noun category to which the property was depicted (e.g., flower). This test was produced for the present experiment to assess Prasada's hypothesis that children are more likely to map adjectives to properties when adjectives are used in the predicate position and objects when used as modifiers. The child's task was to select one of two pictures either a picture of the target property depicted on a new entity (e.g., for piebald, a spotted appearance depicted on a mountain rather than a flower) or target category depicting a new property (e.g., for piebald, a picture of a flower depicting a different property). Two versions of the multiple-choice task were developed to match the testing conditions to the word exposure conditions (see entity set A and B in Table 1).

All measures of adjective knowledge were piloted prior to the experiment to ensure they adequately assessed adjective knowledge (see Best, 2003).

Procedure

Assignment to groups. Prior to running the experiment, the class teachers identified groups of five children to participate in the science lessons. The teacher selected groups that were mixed in terms of gender and academic ability. Each group was randomly assigned to the modification or predication syntax condition, such that half the groups heard adjectives as modifiers and half heard adjectives in the predicate position.

Baseline testing. Baseline testing took place one week prior to running the science lessons. During the baseline test, children worked with the experimenter on an individual basis. The experimenter informed the participants that they were going to carry out science work.

Participants completed the British Picture Vocabulary Scale II (using the standardized instructions) and then the multiple-choice comprehension test. The experimenter administered the BPVS II using the standard procedures. For the multiple-choice task, the experimenter asked the child to select one of the four pictures (e.g. "I would like you to find the piebald thing or thing that is piebald"). Item order was counterbalanced so that half the children encountered the 
Lexical Acquisition in Elementary Science Classes 20

adjectives in the order piebald, coarse, pallid, verdant, luminous and translucent whereas the remaining half encountered the adjectives in the reverse order.

Science classes. The science lessons were conducted in a quiet work space or empty classroom situated near the children's classroom. The experimenter pulled groups of children aside to take part in the science lessons. During the lesson, informed each group of five children was informed that they were going to learn about things that are alive and growing, which involved looking at pictures of things that are alive and things that are not alive. The experimenter then followed the lesson script, cited in the Appendix, in which she asked children what was alive and not alive in the four color posters. After discussing each poster, the experimenter provided a summary of what was in the poster. It was at this point that the exposure adjectives were introduced. When introducing the adjectives, the experimenter mentioned words once (e.g., "This is a piebald flower"). As the experimenter introduced the adjectives she pointed to images of the entities depicting target properties (see Appendix for a full description).

Half the groups were exposed to the adjectives depicted on entity set A whereas half the groups were exposed to adjectives depicted on entity set B as described previously. To control for order effects, the order in which adjectives were presented was varied so that half the groups exposed to entity set A and entity set B heard the exposure adjectives introduced in the order piebald, coarse, verdant and luminous; remaining groups heard the adjectives in the reverse order.

Once the lesson was completed, the experimenter asked all but one child to return to the classroom to continue with their regular classroom work. The remaining child completed the post-tests. Once the first child completed the tests the experimenter escorted him or her back to the classroom, collecting the second child for testing. This procedure was repeated until all five children in the group were tested. Post-testing lasted approximately five minutes per child and thus all participants were tested within thirty minutes of the science classes. 
Lexical Acquisition in Elementary Science Classes 21

Post-test. During the post-test, children first completed the picture-naming test followed by the multiple-choice task and the drawing and definition task. The instructions and procedures used for the multiple-choice task were identical to baseline. For the picture-naming task the experimenter named the entity in the picture (e.g., "This is a picture of a flower") then asked the child to describe the entity (e.g., "I would like you to tell me something about it"). For the drawing assessment, children were asked to draw a picture of the target attributes (e.g., "I would like you to draw a piebald thing or a thing that is piebald"). Children were supplied with coloring crayons. Once the drawing was complete, or the child said that they could not produce a drawing, participants were required to say what they thought each word meant (e.g., "What does piebald mean?"). For the picture-naming, drawing and definition tasks, the order in which items were presented was varied using the same method as the multiple-choice comprehension task as outlined in the baseline testing section. Finally, children completed the adjective generalization task in which they were asked to find the picture the experimenter was referring to (e.g., "I would like you to find the piebald one or the one that is piebald").

\section{Results}

The analysis focuses on (1) effects of adjective learning between baseline testing and the immediate post-test and (2) the extent of knowledge children acquired about word meanings. For the multiple-choice, picture-naming and drawing and definition tasks, accurate responses and error responses on each word knowledge task were totalled and transformed into proportions, such that the number of correct or error responses was divided by four for the exposure adjectives and two for the control adjectives. For the adjective generalization task, the number of property responses was totalled and transformed into proportions for exposure adjectives and control adjectives, respectively.

PPreliminary analyses showed that there were no statistically significant differences in adjective learning as a function of order of adjective presentation, entity set (plant or 
Lexical Acquisition in Elementary Science Classes 22

geographical features) or child-based factors (gender, or children's age assessed in years and months). Finally the point at which the child was tested after the science lesson (first child tested or last child tested), did not affect patterns of results.

Adjective learning

We conducted a preliminary analysis to ensure that effects of learning were not related to the nesting of subjects within the 16 groups (groupings of five children). A hierarchical analysis was conducted using a repeated measures model. Time of Testing (for exposure adjectives) and Syntax (modification or predication) were the repeated measures variables and Group (group in

Formatted: Font: Italic which subjects were trained) was the random factor. The results indicated that there were no statistically significant effects of Group and thus the variable Group is not considered further.

A $2 \times 2 \times 2$ mixed within- and between-subjects ANCOVA was conducted to assess children's performance on the multiple-choice comprehension task at baseline and post-test. The within-subjects variables were Time of testing (baseline and immediate post-test) and Adjective type (exposure or control) and the between-subjects variable was Syntax (modification or predication). Children's BPVS II standardized scores were entered as the covariate. Since the main effect means are adjusted for the covariate in an analysis of covariance, the following result set reports the adjusted means rather than the raw means.

Results from the ANCOVA indicated that after the adjustment for the covariate, there were no statistically significant main or interaction effects of Syntax. However, there were main effects of Time of testing, $F(1,77)=12.68, M S E=0.067, p<0.01$, and Adjective type, $F(1,77)=$ 39.66, MSE $=0.051, p<0.001$, and an interaction between Time of testing and Adjective type, $F(1,77)=15.48, M S E=0.061, p<0.001$. While performance increased for the exposure adjectives between baseline $(M=0.14, S D=0.20)$ and the immediate post-test $(M=0.41, S D=$ $0.28), t(79)=-7.9, p<0.001$, Cohen's $d=1.10$, there was no change in performance for the control adjectives between baseline, $(M=0.15, S D=0.25)$ and the immediate post-test $(M=$ 
Lexical Acquisition in Elementary Science Classes 23

$0.20, S D=0.30), t(79)=-1.21, p>2$. There were no further main or interaction effects.

Receptive vocabulary size (the covariate) was not associated with a significant increase in the proportion of correct responses.

Overall, results from the multiple-choice task indicate that learning had taken place for the exposure adjectives, but not for the control adjectives, regardless of word exposure syntax and children's vocabulary size. To ensure that effects of learning were not related to the nesting of subjects within the 16 groups (groupings of five children), a hierarchical analysis was run using a mixed repeated measures model in which Time of Testing (for exposure adjectives) was the repeated measures variable and Group-(group in which subjects were trained) the randem factor. The analysis confirmed that there was an increase in performance on the exposure adjectives between pre test and post test, with no effects of Group.

\section{Extended mappings}

To assess the kinds of extended mappings children acquired about word meanings, we examined children's accurate responses to the picture-naming task and drawing and definition post-tests.

Picture-naming task. None of the participants correctly named the novel exposure adjectives (or indeed the control adjectives). An analysis of the incorrect responses showed that there were no systematic differences in responses elicited to the exposure adjectives and control adjectives, which suggests that the picture-naming task did not tap effects of word-related acquisition. For the exposure adjectives cChildren commonly produced color terms (expesure adjectives: $M=0.59, S D=0.24$; control adjectives: $M=0.61, S D=0.33)$ ) or markings or texture terms, such as "clear" or "shiny" (exposure adjectives: $M=0.30, S D=0.22$; control adjectives: $M=0.28, S D=0.29$ ). Only a small proportion of children produced category labels, such as "Christmas tree" or "daffodil" (expesure adjectives: $M=0.04, \mathrm{SD}=0.10$; control adjectives: $M$ 
Lexical Acquisition in Elementary Science Classes 24

$=0.03, S D=0.12$ ) or failed to provide a response (exposure adjectives: $M=0.05, S D=0.13$; control adjectives: $M=0.06, S D=0.20$ ). Control words elicited the same kinds of responses.

Drawing and definition tasks. None of the children produced correct drawings or definitions of the target properties. In fact, children commonly failed to produce drawings of referents related to the exposure adjectives (exposure adjectives: $M=0.92, S D=0.21$; control adjectives: $M=0.93, S D=0.20$ ) or definitions (expesure adjectives: $M=0.89, S D=0.91$; eontrol adjectives: $M=0.92, S D=0.28$ ), indicating that children acquired limited understandings of the novel adjectives. This was also the case for the control adjectives.

An analysis of the drawing and definition errors did not show systematic differences in children's responses to the exposure adjectives and the control adjectives. For the drawings, a small number of children produced drawings of irrelevant entities for the exposure adjectives, such as houses and people (exposure adjectives: $M=0.06, S D=0.19$; control adjectives: $M=$ $0.05, S D=0.18$ ) or entities witnessed in the science lessons, such as flowers and mountains (exposure adjectives: $M=0.03, S D=0.02$; control adjectives: $M=0.01, S D=0.05$ ). For the definitions of the exposure adjectives, children produced incorrect definitions, that is, incorrect adjectives, such as rough for the term luminous (exposure adjectives: $M=0.10, S D=0.23$; control adjectives: $M=0.07, S D=0.19$ ) or names of objects witnessed in the science lessons (exposure adjectives: $M=0.01, S D=0.05$; control adjectives: $M=0.01, S D=0.05$ ). $\underline{\text { Again, }}$ analyses exploring children's drawings and definitions of the control adjectives elicited similar responses.

Adjective generalization task. The generalization task assessed whether children were more likely to associate the target adjectives with target properties or the objects on which the properties were depicted. Our analysis focused on the proportion of property responses, which were analyzed with a 2x2 mixed within and between-subjects ANCOVA. The within-subjects variable was Adjective type (exposure or control) and the between-subjects variable was Syntax 
Lexical Acquisition in Elementary Science Classes 25

(modification or predication). Children's BPVS II standardized scores were entered as the covariate. After adjustment for the covariate, there were no statistically significant effects of Syntax or-- Word Type and there was no interaction between Syntax and Word Type;

(Modification exposure adjectives: $M=.44, S D=.28$; Modification control adjectives: $M=.41$, $S D=.34 ;$ Predication exposure adjectives: $M=.47, S D=.37$; Predication control adjectives: $M$ $=.42, S D=.34$ ). Finally, receptive vocabulary size (the covariate) was not associated with a significant increase in the proportion of correct responses. Overall, findings from Experiment 1 provide no support for the hypothesis that adjectives used as modifiers draw attention to categories whereas adjectives used in the predicate position draw attention to properties.

Summary of results from Experiment 1

Findings from Experiment 1 did not provide support for the hypothesis that modifiers draw attention to categories whereas predicates draw attention to properties. Most importantly however, data from Experiment 1 marked limits in children's abilities to identify the meanings of adjectives in discourse. The syntactic cues (modification or predication syntax) may have been sufficient for facilitating the acquisition of vocabulary recognition knowledge, fas reflected in the learning gains on the multiple-choice task). However, the exposure did not produce learning as measured by more stringent measures of word knowledge, namely the picture-naming, drawing and definition tasks., but did not extend to other lexical dimensions.

It is difficult to determine what children understood about word meanings based on their selection of the correct picture from a set of multiple-choice items. The careful choice of distracter items suggests that some lexical specific knowledge was present. However, responses may be indicative of strategic guessing. For example, children's ability to rule out alternatives may stem from a very vague knowledge of the terms denotation. Based on the incorrect responses to the picture-naming, definition and drawing tasks administered at post-test, we can 
Lexical Acquisition in Elementary Science Classes 26

conclude that children's performance on the multiple-choice task was indicative of fragile and incomplete lexical knowledge at best, or a function of strategic guessing at worst.

Minimal 'fast mapping' for adjectives occurs in simple exposures in science lessons. The extend to which learning can be extended by different exposures was examined in Experiment 2 Experiment 2 examines children's acquisition patterns across forms of linguistic and physical scaffolding that are thought to facilitate lexical acquisition.

\section{Experiment 2}

Experiment 2 was designed to identify kinds of scaffolding provided during word exposure that help children acquire novel adjectives. We were interested in methods of verbal and physical scaffolding that support more extensive understandings of word meanings, and investigating relationships between forms of lexical knowledge. The verbal scaffolding drew attention to the semantic aspects of the referent through the use of synonyms such as "It is a coarse leaf. Coarse means rough.” Experiment 2 also investigated whether verbal scaffolding, henceforth called semantic scaffolding used in combination with physical scaffolding was more successful in supporting adjective acquisition than semantic scaffolding only. We selected a method of physical scaffolding expected to draw attention to target properties; when showing children bunches of flowers the experimenter touched parts of the flower that depicted the target properties. Experiment 2 did not include a physical scaffolding only condition because linguistic information is needed to help children acquire extensive word knowledge (i.e., definitional knowledge). Also, it is unlikely that teachers would emphasize properties without providing any linguistic support.

The general structure of Experiment 2 followed that of Experiment 1. A new sample of children drawn from the same grade level was introduced to the exposure adjectives in mock science lessons. Groups of five children participated in the lessons. However, unlike Experiment 1 , novel adjectives were introduced in modification syntax only, because Experiment 1 did not 
Lexical Acquisition in Elementary Science Classes 27

reveal differences in adjective acquisition as a function of adjective syntax. All target properties were depicted on plants because adjective acquisition in Experiment 1 was not affected by entity type.

We predicted that the synonyms would help children acquire more extensive lexical knowledge than the Experiment 1 exposures. However, the combination of semantic and physical scaffolding, which offers more information about word meanings, was expected to be more successful in facilitating lexical acquisition than semantic scaffolding alone. We also predicted that accurate naming is more likely to occur for children who demonstrate semantic knowledge, that is, draw and define the adjectives.

\section{Method}

\section{Participants}

Sixty children with English as their first language were drawn from three science classes based in two schools in a suburban part of Southeast England. Participants were drawn from Year 1 classes, comprising five to six-year old children (children would be classified as either kindergarten or Grade 1 level in the United States.). Children were aged 5;1 to 6;8 (Mean age $=$ $5 ; 9, S D=0.42)$.; twenty-seven were males and thirty-three females. 
Lexical Acquisition in Elementary Science Classes 28

\section{Design}

To assess effects of adjective learning, we assigned children to one of three conditions; 1 ) combination condition; 2) synonym only condition; or 3) control condition. For children in the Combination condition, the experimenter provided synonyms and touched parts of a flower she was showing children to emphasize the target properties; for children in the synonym only condition, the experimenter provided synonyms when showing children the flowers, but did not emphasize the target properties. Children in the control condition did not participate in the science lessons, but merely completed the baseline and post-test tasks. As we used a control condition, we did not assess knowledge of the control adjectives included in Experiment 1.

\section{Materials}

The materials were in most respects, identical to Experiment 1 . Adjustments to the materials are reported here.

Word exposure materials. In terms of the science lesson materials, we modified the word exposure script to incorporate the use of synonyms (see Appendix). Concrete referents (artificial flowers) were used to implement the physical scaffolding as opposed to pictured entities used in Experiment 1 . The experimenter could meaningfully emphasize the target properties using touch when showing children concrete referents.

Word knowledge tasks. The multiple-choice comprehension task used at baseline and the post-test and the picture-naming task used at post-test were modified so they included only pictures of flowers. An adjective generalization task was not included in this experiment.

\section{Procedure}

Again, the procedures were in most respects, identical to Experiment 1. Adjustments to the procedures are reported here. 
Lexical Acquisition in Elementary Science Classes 29

Allocation to condition. After the classroom teacher identified sets of five children to work together in the science lessons, the experimenter randomly assigned each group of five children to the experimental or control conditions.

Post-testing. It is important to point out that during testing children in the combination group were not provided with physical scaffolding used in the word exposure situation.

\section{Results}

Following the format of Experiment 1, the analysis focused on the adjective learning and the extent of knowledge children acquired. The analysis also focused on the relationship between children's accurate naming and acquisition of semantic knowledgeperformance on the drawing and definition assessments. Correct responses on each of the tasks were totalled, such that children could score between 0 and 4 . Totals were then transformed into proportion scores by dividing the total score by four.

PPreliminary analyses showed that performance on the word knowledge tasks was not affected by order of presentation or child-based factors (gender, or children's age assessed in years and months) and thus, these variables are not considered further. Furthermore, preliminary tests showed that there were no differences in receptive vocabulary scores among children in the combination, definition only and control groups. Finally, the point at which the child was tested after the science lesson (first child tested or last child tested) did not affect the patterns of results. Adjective learning

As with Experiment 1, we conducted a preliminary analysis to ensure patterns of learning were not affected by the nesting of subjects within the 12 groups (groupings of five children). A hierarchical mixed repeated measures model was run in which Time of Testing was the repeated measures variable, Condition the fixed factor, and Group (group in which subjects were trained) 
Lexical Acquisition in Elementary Science Classes 30

the random factor. The results indicated that there were no statistically significant effects of Group and thus the variable Group is not considered further.

Using the correct scores on the multiple-choice task, a 2x3 mixed-model ANCOVA was conducted with Time of testing (baseline or post-test) as the within-subjects factor, Condition (combination, synonym only or control) as the between-subjects factor and children's BPVS II standardized scores as the covariate. Again, following Experiment 1, the following result set reports the adjusted means rather than the raw means.

As illustrated in Table 2, tThere was a main effect for Time of testing, $F(1,56)=54.17$, $M S E=0.049, p<0.001$, and also a main effect of Condition, $F(1,56)=9.46, M S E=0.060, p<$ 0.01. There was also a statistically significant interaction between Time of testing and Condition, $F(2,56)=9.62, M S E=0.049, p<0.01$, indicating that performance on the multiple-choice task increased for children in the combination condition and synonym only condition, but not the control condition. (see Table 2).

To tap into the effect of Condition, a post-hoc test of multiple comparisons with a Bonferroni adjustment for alpha was conducted. post-hoc test of multiple comparisons was conducted. There were significant differences in adjective learning between children in the combination condition and control condition, $p<0.001$, Cohen's $d=1.78$, and synonym only condition and control condition, $p<0.001$, Cohen's $d=1.38$, but not the combination condition and synonym only condition, $p>0.05$. There were no other statistically significant effects, including effects of receptive vocabulary size. Finally, receptive vocabulary size (the covariate) was not associated with a significant increase in the proportion of correct responses. Overall, exposure to the adjectives in the synonym only and combination conditions facilitated adjective learning, but effects of learning were not related to vocabulary size.

As with Experiment 1, exposure to the novel adjective yielded effects of learning and learning was not related to vocabulary size. To check that effects of learning were not affected 
Lexical Acquisition in Elementary Science Classes 31

by the nesting of subjects within the 12 groups (groupings of five children), a mixed repeated measures model was run in which Time of Testing was the repeated measures variable, Condition the fixed factor, and Group (group in which subjects were trained) the random factor. The same patterns of significance identified in the ANCOVAs were obtained. There were no statistically significant effects of group.

INSERT TABLE 2 ABOUT HERE

\section{Extended mappings}

As before, to check whether correct performance was related to subject grouping (nesting of subjects within the 12 groups), hierarchical analyses were run using linear models on the extended knowledge data. In each analysis, Condition was the fixed factor, Group (group in which subjects were trained) the random factor and children's standardized BPVS II scores the covariate. The dependent variable was children's proportion correct score on the knowledge assessment tasks. The results indicated that there were no statistically significant effects of Group and thus the variable Group is not considered further.

To assess children's acquisition of extended word knowledge, three univariate ANCOVAs were conducted, with Condition (combination, synonym only or control) as the between-subjects variable, children's standardized BPVS II scores as the covariate, and proportion correct scores to each form of assessment (picture-naming, drawing and definition) as the dependent variables. The proportion correct scores for children in each group are reported in

Table 3. Again, adjusted mean scores are reported rather than raw mean scores.

Post-hoc tests of multiple-comparisons with a Bonferroni adjustment for Alpha were Bonferroni post hoc tests of multiple comparisons were-conducted to examine effects of learning as a function of Condition (combination, synonym only and control). As there were three posttests (picture-naming, drawing and definition assessments) alpha levels were adjusted to control 
Lexical Acquisition in Elementary Science Classes 32

for type I errors (alpha was set at 0.016 ). Thus, to be valued as statistically significant at the 5\% level, the p-value was to be less than 0.016 .

Picture-naming. Levels of accurate naming were low. However, the ANCOVA analysis indicated that after the adjustment for the covariate there was a main effect of Condition, $F(3,56)$ $=5.12, M S E=0.015, p<0.01$. A Bonferroni post-hoc test of multiple comparisons showed that the combination condition performed significantly better than the control condition, $p<0.016$, Cohen's $d=.89$. The combination condition did not perform significantly better than the synonym only condition, $p=0.05$, Finally, the synonym only condition did not perform significantly better than the control condition, $p>0.5$. There was a trend approaching statistical significance, indicating that the covariate (children's receptive vocabulary size) was associated with picture-naming, $F(3,56)=2.80, M S E=0.038, p=0.09$. There was a positive correlation between receptive vocabulary size and picture-naming, $r(N=60)=.28, p<0.05$, indicating that children with larger receptive vocabularies were more likely to accurately name the target adjectives.

Definitions. After the adjustment for the covariate, there was a main effect of Condition, $F(3,56)=12.25, M S E=0.032, p<0.001$. A Bonferroni post-hoc test of multiple comparisons showed that the combination condition performed better than the control condition, $p<0.016$, Cohen's $d=1.17$. Again, there were no statistically significant differences in performance between the combination condition and the synonym only condition, $\mathrm{p}>0.016$, or the synonym only condition and the control condition, $p>0.2$. The covariate, children's receptive vocabulary size was also statistically significant, $F(3,56)=10.12, M S E=0.032, p<0.01$. There was a positive correlation between receptive vocabulary size and the production of the correct definitions, $r(N=60)=.40, p<0.01$, indicating that children with larger receptive vocabularies were more likely to produce correct definitions. 
Lexical Acquisition in Elementary Science Classes 33

Drawings. As with the definition data, after the adjustment for the covariate, there was a main effect of Condition, $F(3,56)=7.55, M S E=0.034, p<0.01$. A Bonferroni post-hoc analysis showed that the combination condition performed better than the control condition, $p<0.016$, Cohen's $d=1.46$. As with the definition data, there were no statistically significant differences between the combination condition and the synonym only condition, $p>0.016$ or the synonym only condition and the control condition, $p>0.05$. The covariate, children's receptive vocabulary size, was also significant, $F(1,56)=5.3, M S E=0.034, p<0.05$. Again, there was a positive correlation between receptive vocabulary size and drawings that included correct features, $r(N=$ $60)=.36, p<0.01$, indicating that children with larger receptive vocabularies were more likely to produce drawings containing the target properties.

In summary, the post-tests indicated that children in the experimental groups acquired extended word knowledge. Accurate performance on the post-tests was related to receptive vocabulary size. As before, to check whether effects of learning were related to subject grouping (nesting of subjects within the 12 groups), hierarchical analyses were run using mixed linear models on the extended knowledge data. In each analysis, Condition was the fixed factor, Group (group in which subjects were trained) the random factor and children's standardized BPVS II scores the covariate. The dependent variable was children's proportion correct score on the knowledge assessment tasks. The same patterns of significance identified in the ANCOVAs were өbtained. There were no statistically significant effects of group.

\section{INSERT TABLE 3 ABOUT HERE}

\section{Relationships between lexical knowledge}

The final analysis investigated relationships between lexical knowledge children acquired. Our focus was on the post-test scores and thus whether accurate naming, which relatively few children achieved, is associated with the acquisition of semantic knowledge. To explore the relationship between accurate naming and other lexical knowledge, correlation 
Lexical Acquisition in Elementary Science Classes 34

analyses were conducted using the correct scores on the multiple-choice comprehension, picture-naming, drawing and definition post tests. Correlations were performed using data generated by children in the combination only group $(\mathrm{N}=20)$; correlations were not performed from children in the synonym only group or control group because levels of naming amounted to $2 \%$ and zero, respectively.

Table 4 shows that accurate naming was significantly correlated with correct performance on the drawing and definition tasks. However, there was no statistically significant correlation between accurate naming and comprehension (as measured with the multiple-choice task).

There was a strong positive relationship between accurate drawings and accurate definitions, indicating that the two tasks were both successful in tapping semantic knowledge. Although the definition and drawing data was tapping semantic knowledge, we used definition data only in the regression analyses. Definition data was selected over drawing data because definition tests are more conventional measures of semantic knowledge.

Summary of results from Experiment 2

Results from Experiment 2 showed that semantic scaffolding plays an important role in driving adjective acquisition and is especially important for helping children acquire extended word knowledge; children offered synonyms acquired more extensive lexical knowledge than children in Experiment 1 who did not encounter semantic scaffolding. However, children's success in utilizing semantic input to acquire extended mappings was related to their pre-existing vocabulary size.

There was some evidence to show that a combination of semantic and physical scaffolding helped 4-6 year old children acquire novel adjectives. On the multiple-choice task, children in the combination condition performed better than children in the synonym only condition and the control condition. The extended knowledge tasks (picture-naming, definition 
Lexical Acquisition in Elementary Science Classes 35

and drawing) also demonstrated the importance of combined semantic and physical scaffolding.

While there were no significant differences in accurate performance between children in the combination condition and synonym only condition, children in the combination condition significantly outperformed control children whereas children in the synonym only condition did not out perform controls. Thus, the convergence of findings suggests a combination of physical and semantic scaffolding was more successful in facilitating lexical acquisition than semantic scaffolding alone.

\section{Discussion}

It is well established that the scaffolding children encounter about word meanings during word exposure plays a critical role in facilitating lexical acquisition. The aim of the study was to expand our understanding of the ways in which ielassreom based-nstructional scaffolding $\underline{\text { in }}$ small groups helps children acquire novel words. We focused on the types of lexical item encountered in science classes (e.g., novel adjectives) together with the nature of information teachers offer children about meanings of novel words introduced in science classes (e.g., verbal information and physical scaffolding). The findings extend previous research evidence by providing a more detailed picture of the representations (or lack thereof) children develop in simple single exposures. Findings from Experiment 2 demonstrate the ways in which teacher scaffolding can address the limitations of simple single exposures. The following discussion presents a synopsis of the main findings and implications for supporting word learning and assessing lexical knowledge in the classroom.

Summary of the main findings

Previous research with children at the pre-school and school level has shown that children are competent word learners who capitalize on a range of informational sources to acquire word meanings, including syntactic cues, semantic cues and reference to visual referents (e.g., Clark \& Wong, 2002; Ralli, 1999; Elley, 1989; Biemiller \& Boote, in press). While 
Lexical Acquisition in Elementary Science Classes 36

children can acquire words from context, with minimal scaffolding, words are acquired more successfully when direct semantic information is available (e.g., Nelson, 1996; Elley, 1989;

McKeown \& Beck, 2004; Penno et al, 2002; Brabham \& Lynch-Brown, 2002). Our research investigated the manner in which children cope with adjectives commonly encountered in science classes when offered no semantic information (Experiment 1) and when offered explicit semantic information (Experiment 2). In combination, the experiments have allowed for the assessment of the role of semantic scaffolding and physical scaffolding in lexical acquisition and the nature of children's lexical representations.

Adjective learning. Results from the two experiments corroborate with previous evidence to suggest that semantic input plays a primary role in supporting word learning (e.g., Biemiller \& Boote, in press; Clark, 1997; Clark \& Wong, 2002). The percentage learning gain (increase in performance from pre-test to post-test on the multiple-choice task) was higher in Experiment 2 (for children in the experimental conditions) than children in Experiment 1 (when tested on the exposure adjectives).

Importantly, results from Experiment 2 indicated that a combination of semantic and physical scaffolding facilitated higher levels of adjective learning than semantic scaffolding only. The percentage learning gain among children in the combination group was higher (51\%) than the percentage learning gain among children in the synonym only group (31\%). In accordance with recent pre-school research, children acquire adjectives more successfully when offered both verbal and physical support (Mintz \& Gleitman, 2002). Research with school-age children also shows that a combination of explanations and text pictures facilitates vocabulary acquisition during narrative reading (e.g., Senechal).

Extended mappings. The convergence of findings from Experiment 1 and Experiment 2 strengthen our understanding of the ways in which teacher scaffolding supports the acquisition of extended mappings. Our data indicate that semantic scaffolding is of critical importance. 
Lexical Acquisition in Elementary Science Classes 37

Experiment 2 children, who were offered semantic scaffolding, or semantic and physical scaffolding were successful in acquiring extended mappings (picture-naming and the production of accurate definitions and drawings). However, Experiment 1 children who did not encounter semantic scaffolding were unsuccessful in acquiring extended mappings. Together, the results indicate that single exposures in which adjective meanings are not directly specified are sufficient to begin the mapping process, but not the acquisition of more complete understandings (Carey, 1978; Nelson, 1996; Ralli, 1999; McKeown \& Beck, 2004). Conversely, single exposures that incorporate semantic scaffolding facilitate the acquisition of deeper, more extended knowledge (e.g., Biemiller \& Boote, in press; Ralli, 1999). Interestingly, most previous classroom investigations indicate that deeper knowledge is acquired following multiple episodes of instruction (e.g., Biemiller \& Boote, in press). However, data from Experiment 2 indicate that teachers can support extended mappings from a single exposure by providing semantic scaffolding.

However, the Experiment 2 extended knowledge data (picture-naming, definition and drawing tasks) indicated that children's ability to utilize semantic information was related to vocabulary size (e.g., Robbins \& Ehri, 1997). Children with larger vocabularies have a larger general knowledge base and thus are more successful in drawing on semantic information about word meanings, such as synonyms (Stanovich, 1995). Interestingly, results from Experiment 1 and Experiment 2 showed that vocabulary size was not associated with the acquisition of receptive vocabulary knowledge (as assessed using the multiple-choice comprehension task).

This result, also evidenced in previous research (Ralli \& Dockrell, in press $\underline{2005}$ ), may suggest that children's ability to use semantic information drives the acquisition of extended word knowledge rather than fragile, word recognition knowledge.

Moreover, findings from Experiment 2 offer some support for the view that that a combination of semantic scaffolding and physical scaffolding is more successful than semantic 
Lexical Acquisition in Elementary Science Classes 38

scaffolding alone in supporting extended adjective mappings. While- children in the combination and synonym only group performed at similar levels, children in the combination group outperformed control children on the picture-naming, definition and drawing tasks, whereas children in the synonym only task did not outperform controls. Drawing attention to physical referents appears to bolster semantic information, which, in turn facilitates the acquisition of extended mappings. Thus, it is important that future classroom studies investigating word learning in expository domains pay greater attention to non-verbal as well as verbal methods of scaffolding.

Representations of lexical knowledge. The Experiment 2 data offered a valuable insight into the nature of children's newly acquired lexical representations. Of children who acquired extended word knowledge, few accurately named the novel adjectives. Difficulties with production suggests that accurate naming may present greater difficulty for acquisition and perhaps represents a more advanced form of word knowledge (Ralli, 1999; Best et al, 2006). Certainly, production is more cognitively demanding than comprehension as children must actively retrieve the word from memory as well as invoke recognition memory (Huttenlocher, 1974; Messer \& Dockrell, in press). Perhaps more interesting, our data implicate that accurate naming builds onto the acquisition of semantic knowledge (McGregor et al, 2002), Our findings show that children who accurately named the novel adjectives tended to have acquired rich semantic knowledge (i.e., definitional knowledge). According to McGregor et al (2002), the degree of knowledge represented in the semantic lexicon makes words more or less vulnerable to retrieval failure, such that limited semantic knowledge results in a greater likelihood of retrieval failure.

When considering children's naming proficiency, we must also consider the demand characteristics of the task to interpret the low-levels of accurate naming. The picture-naming task may easily elicit the "incorrect" response. There are many acceptable names for referents, not 
Lexical Acquisition in Elementary Science Classes 39

just the target response. Thus, it may be important for future research to identify alternative methods to elicit representations, over and above the picture-naming task.

\section{Implications}

Findings from the research have implications for both helping children acquire new words commonly encountered at school and the measurement of lexical knowledge in classroom settings. It is encouraging to observe that teachers' introductions to novel terms helps children acquire new words. However, there is a clear difference in the learning gains observed and the quality or level of lexical representations children acquire (Beck \& McKeown, 1991). Word learning success is intricately related to the nature of scaffolding provided. In terms of implications for lexical acquisition in the classroom our findings highlight the importance of offering children direct and explicit information about word meanings, such as brief definitions or synonyms (e.g., Graves, 1986; Beck \& McKeown, 1991; Penno et al, 2002). However, due to the large number of words children encounter each day, it would be impossible to offer direct information about all new terms. Thus, teachers are required to prioritize words with respect to which words are most important to teach and explain.

Educational researchers acknowledge the problem regarding the logistics of teaching word meanings and recommend that the teacher offer instruction or support for particular kinds of words. Important words include those that are fundamental to understanding a specific reading or concept and words that are generally useful to know and are likely to encounter with some frequency (Beck, McKeown, \& Kucan, 2002; Biemiller, 2004; Bielmiller \& Slomin, 2001). Beck et al (2002) identified important words using a three-tier classification system, in which tierTier two words are reported to be important for teaching. One tierTier one words consist of terms, such as "baby" and "happy", whose meanings students are likely to know. Two tierTier two words comprise terms such as "fortunate" and "merchant", which occur frequently in oral and written language, but are less likely to be known to students. Three-tierTier three words, 
Lexical Acquisition in Elementary Science Classes 40

such as "retinue" and "irksome" are classified as "rare" terms that are infrequently used and unlikely to be known to many children.

It could be argued that the words used in the present experiment do not fit the twotierTier two category. However, in content domains, such as science children encounter a wide range of vocabulary, including words that may be "rare" in everyday use (e.g., children's books). However, the words selected for the experiment were related to concepts taught in the National Curriculum for England and Wales (Department for Education and Employment, 1999). Indeed, curriculum guidance documents for England and Wales stress the importance of learning scientific language as they form the building blocks of domain knowledge. Overall, when deciding which words to teach, it is important that educators consider the subject domain and how lexical items contribute to the understanding of subject domains. For example, if a word relates to an important curriculum concept, it is important to offer instruction about the word, even if it is rarely used in everyday teaching contexts. Furthermore, experts in science education postulate that the value of teaching a particular word in science will depend on what the child already knows and whether they have a lexical gap to fill; children are more likely to grasp understandings of word meanings when they have some prior conceptual knowledge (Wilson, 1998; Harlen, 2000). Thus, an important first step in deciding whether to teach a word may be to judge the nature of children's knowledge for the target domain.

To establish what the child knows about word meanings it is important to identify methods useful for assessing lexical knowledge. Findings from our study have important implications for how we might best assess children's word knowledge. Data from Experiment 1 indicate that caution needs to be taken in interpreting results from multiple-choice and picturenaming assessments. The multiple-choice test is a "flat" measure of comprehension (Beck \& McKeown, 1991) selecting the correct answer does not tell us how well a word is known. Further, there is a danger that multiple-choice items are not tapping lexical-specific knowledge. 
Lexical Acquisition in Elementary Science Classes 41

Thus, it is important that multiple-choice assessments are not used in isolation, but in combination with other word knowledge assessment tools, such as naming and definition tasks. Picture-naming tasks are stringent forms of lexical knowledge assessment, but may easily elicit the "wrong answer" (see above discussion). Consequently, picture-naming tasks may be less valid tools for assessing whether a word has been acquired.

The Experiment 2 data indicate that drawing assessments, which are widely used in school settings (in addition to definitional assessments), are useful for assessing what the child knows about a word. There was a strong positive correlation between children's ability to produce accurate definitions and drawings, indicating that the drawing assessment was tapping into semantic knowledge. An advantage of drawing assessments is that they eliminate problems with verbal expression, sometimes encountered by young children (Rennie and Jarvis, 1995). Further, recent research indicates that drawing assessments can be more effective than verbal assessments for eliciting particular kinds of concept knowledge, such as knowledge of science concepts or shape and size (Gross \& Teubal, 2001).

\section{Limitations and future research}

The present study has gone some way to further our knowledge of word learning during classroom-basedsmall-group learninginstruction, especially with respect to the nature of knowledge children acquire from typical exposures to novel adjectivesabout word meanings.However, there were several limitations to the study, which merit discussion. Firstly, while differences in word learning success observed in Experiment 1 and Experiment 2 implicate the importance of semantic and physical scaffolding, we need to add a cautionary note about differences in stimulus materials used in the two experiments. It is possible that differences in learning across the experiments was affected by the pictured entities used in Experiment 1 and concrete referents (artificial flowers) used in Experiment 2. The artificial flowers may have been more engaging and interesting to children, or depicted the target properties more obviously. 
Lexical Acquisition in Elementary Science Classes 42

Future research should ensure that the same stimulus materials are maintained across experiments to control for potential scaffolding effects of visible referents.

Secondly, while we stressed the importance of lexical item and teaching context in classroom-based word learning, we focused on adjectives only, in one science teaching context. As children progress through the school years they encounter words that are abstract, domain specific and domain general and involve non-literal meanings (Nagy, Diakidoy, \& Anderson, 1993; Nippold, Cuyler, \& Braunbeck-Price, 1988; Smiley \& Huttenlocher, 1995). Establishing semantic representations for entities that are not easily seen, heard or touched may prove to be especially difficult (Dockrell, Braisby \& Best, under review; Nippold, 1998) and thus it is important that we investigate the kinds of exposures that support the acquisition of more “complex" vocabulary items.

Finally, we focused on a limited range of exposure contexts. The nature of information available to children and the number of encounters with a word will vary as a function of subject domain and teaching activity. For instance, during episodes of science instruction, in which teachers frequently draw on the use of visual aids, they may use a lot of physical scaffolding; in story reading contexts, in which teachers read books on numerous occasions, teachers may reintroduce target words on several occasions. In sum, there is clearly scope for further classroom-based research to examine how children acquire different kinds of words across teaching domains and activities. 
Lexical Acquisition in Elementary Science Classes 43

\section{References}

Anglin, J. (1993). Vocabulary development: A morphological analysis. Monographs for Social Research and Child Development, 58, Serial No. 238.

Baldwin, D. A. (1991). Infants Contribution to the Achievement of Joint Reference. Child Development, 62 (5), 875-890.

Baumann, J. F., \& Kameenui, E. J. (1991). Research on vocabulary instruction: Ode to Voltaire. In J. Flood, J. J. D. Lapp, \& J. R. Squire (Eds.), Handbook of research on teaching the English language arts (pp. 604-632). New York: MacMillan.

Baumann, J. F., Kame'enui, E. J., \& Ash, G. E. (2003). Research on vocabulary instruction: Voltaire redux. In J. Flood, D. Lapp, J. R. Squire, \& J. M. Jensen (Eds.)

Beck, I. L., \& McKeown, M. (1991). Conditions of vocabulary acquisition. In R. Barr, M. L. Karmil, P. Mosenthal, \& D. D. Pearson (Eds.), Handbook of Reading Research (Vol. 1), Longman Publishing Group.

Beck, I. L., McKeown, M. G., \& Kucan, L. (2002). Bringing words to life: Robust vocabulary instruction. New York: Guilford.

Beck, I. L., McKeown, M., \& McCaslin, E. S., (1983). All contexts are not created equal. Elementary School Journal, 83, 177-181.

Best, R. M., (2003). Lexical acquisition in naturalistic contexts. Unpublished Doctoral thesis, South Bank University, London.

Best, R., Dockrell, J. E., \& Braisby, N. (2006). Real world word learning: Exploring children's developing semantic representations of a science term, British Journal of Developmental Psychology, 24, 265-282. 
Lexical Acquisition in Elementary Science Classes 44

Biemiller, A. (2004). Teaching vocabulary in the primary grades: Vocabulary instruction needed. In J. Baumann and E. Kame'enui (Eds.). Reading vocabulary: Research to practice, pp 28-40. New York, NY: Guilford Press.

Bielmiller, A., \& Boote, C. (in press). An effective method of building vocabulary in primary grades, Journal of Educational Psychology.

Biemiller, A., \& Slonim, N. (2001). Estimating Root Word Vocabulary Growth in Normative and Advantaged Populations: Evidence for a Common Sequence of Vocabulary Acquisition Journal of Educational Psychology, 93, 498-520.

Best, R. M., (2003). Lexical acquisition in naturalistic contexts. Unpublished Doctoral thesis, South Bank University, London.

Best, R., Dockrell, J. E., \& Braisby, N. (2006). Real World Word Learning: Exploring Children's Developing naming Representations of a Science Term, British Journal of Developmental Psychology.

Blatchford, P., \& Kutnick, P. (2004). Developing groups work in everyday classrooms. In: P. Blatchford, \& P. Kutnick, P. (Eds.). Special Issue of the International Journal of Educational Research, 39, 1-7.

Bloom, L. (1997). Language acquisition in its developmental context. In D. Kuhn \& R. Siegler (Eds.), The handbook of child psychology: Vol. 2, Cognition, perception, and language. New York: Wiley.

Bloom, P. (2000). How Children Learn the Meanings of Words. Cambridge MA, MIT Press.

Booth, A. E., \& Waxman, S. R. (2002). Word learning is smart: evidence that conceptual information affects pre-schoolers' extension of novel words. Cognition, 84, B11 - B22.

Bornstein, M. H., Cote, L. R., Maital, S., Painter, K., Park, S-Y., Pascual, L., Pêcheux, M-G., Ruel, J., Venuti, P., \& Vyt, A. (2004). Cross-Linguistic Analysis of Vocabulary in Young 
Lexical Acquisition in Elementary Science Classes 45

Children: Spanish, Dutch, French, Hebrew, Italian, Korean, and American English. Child Development, 75, 1115-1139.

Bowey, J. A. (1996). On the association between phonological memory and receptive vocabulary in five-year olds. Journal of Experimental Child Psychology, 63, 44-78.

Bowey, J. A. (2001). Nonword repetition and young children's receptive vocabulary: A longitudinal study. Applied Psycholinguistics, 22 (3), 441-469.

Brabham, E. G., and Lynch-Brown, C. (2002). Effects of teachers' reading-aloud styles on vocabulary acquisition and comprehension of students in the early elementary grades. Journal of Educational Psychology, 94, 465-473.

Brett, A., Rothlein, L., \& Hurley, M. (1996). Vocabulary acquisition from listening to stories and explanations of target words. The Elementary School Journal, 96, 415-422.

Brown, G.D.A. (1984). A frequency count of 190,000 words in the London-Lund Corpus of English Conversation. Behavioural Research Methods Instrumentation and Computers, 16, 502-532. Burroughs, G.E.R. (1957). A study of vocabulary of young children. Birmingham: Oliver Boyd.

Carey, S. (1978). The child as word learner. In M. Hale, J. Bresman and G. A. Miller (Eds.), Linguistic theory and Psychological reality (pp. 264-93). Cambridge MA: MIT Press.

Carey, S. (1986). Cognitive science and science education. American Psychologist, 41, 1123-1130.

Carlisle, J. F., Fleming, J. E., \& Gudbrandsen, B. (2000). Incidental word learning in science classes. Contemporary Educational Psychology, 23, 164-211.

Chall, J. S., Jacobs, V. A., and Baldwin, L. E. (1990). The reading crisis: Why poor children fall behind. Cambridge, MA: Harvard University Press.

Clark, E. V. (1997). Conceptual perspective and lexical choice in acquisition. Cognition, 64, 1-37.

Clark, E. V., \& Wong, A. (2000). Pragmatic directions about language use: Words and word meanings. Language in Society, 31, 181-212. 
Lexical Acquisition in Elementary Science Classes 46

Curtis, M. E. (1987). Vocabulary testing and instruction. In M. G. McKeown \& M. Curtis (Eds.), The nature of vocabulary acquisition, Hillsdale NJ: Erlbaum.

Deák, G. O. (2000a). The growth of flexible problem-solving: Preschool children use changing verbal cues to infer multiple word meanings. Journal of Cognition and Development, 1, 157192

Deák, G. (2000b). Chasing the fox of word meaning: Why "constraints" fail to capture it. Developmental Review, 20, 29-80.

Deák, G. O., \& Wagner, J. H. (2003). "Slow mapping" in children’s learning of semantic relations. Proceedings of the Annual Conference of the Cognitive Science Society.

De Jong, P. F., Seveke, M . J., \& van Veen, M. (2000). Phonological sensitivity and the acquisition of new words in children. Journal of Experimental Child Psychology, 76, 275301.

Department for Education and Employment. (1999). The National Curriculum: Handbook for primary teachers in England. London: Department for Education and Employment.

Dockrell, J. E., Braisby, N., \& Best, R. M. (submitted). Children's acquisition of science terms: simple exposure is insufficient, Learning and Instruction.

Dockrell, J. E., \& McShane, J. (1990). Young children's use of phrase structure and inflectional information in form-class assignments of novel nouns and verbs. First Language, 10, 127-140.

Dockrell, J. E. \& Messer, D. J. (2004). Later vocabulary acquisition. In R. Berman, Language development across childhood and adolescence: Psycholinguistic and crosslinguistic perspectives, Trends in Language Acquisition 3, (pp 35-52), John Benjamins Publishing Company.

Dockrell, J. E., Messer, D., \& George, R. (2001). Patterns of Naming Objects and Actions in Children with Word Finding Difficulties, Language and Cognitive Processes, 16, 261-286. 
Lexical Acquisition in Elementary Science Classes 47

Dove, J. E., Everett, P. F. W., \& Preece, P. F. W. (1999). Exploring a hydrological concept through children's drawings. International Journal of Science Education, 21, 485-497.

Driver, R., Squires, A., Rushworth, P., \& Wood-Robinson, V. (1994). Making sense of secondary science. London: Routledge.

Dunn, L. M, Dun, L. M., Whetton, C. \&, Burley, J. (1987). The British Picture Vocabulary Scale. $2^{\text {nd }}$ edition. Windsor: NFER-Nelson.

Elley, W. B. (1989). Vocabulary acquisition from listening to stories. Reading Research

Quarterly, 24, 174-186.

French, L., \& Peterson, I. (2005). Learning language through pre-school science. Symposium presentation for the Eleventh Biennial European Association for Research on Learning and Instruction Conference, Nicosia, Cyprus.

Gillette, J., Gleitman, H., Gleitman, L., \& Lederer, A. (1999). Human simulations of vocabulary learning. Cognition, 73, 135-176.

Gleitman, L. R. (1990). The structural sources of word meaning. Language Acquisition, 1, 3-55.

Goodman, J. C., McDonough, L., \& Brown, N. (1998). The role of semantic context and memory in the acquisition of novel nouns. Child Development, 69, 1330-1344.

Graves, M. F. (1986). Vocabulary learning and instruction. In E. Z. Rothkopf (Ed.), Review of research in education , 13 , 49-89.

Graves, M. F. (2000). A vocabulary program to complement and bolster a middle-grade comprehension program. In B. M. Taylor, M. F. Graves and P. van den Broek (Eds.), Reading for meaning: Fostering comprehension in the middle grades (pp. 116-135). New York: Teachers College Press; Newark, DE: International Reading Association.

Graves, M. F. (2006). Vocabulary learning and instruction. New York: Teachers College Press.

Graves, M. F., Juel, C. \& Graves, B. B. (2004). Teaching reading in the $21^{\text {st }}$ century ( $3^{\text {rd }}$ edition). Boston: Allyn \& Bacon. 
Lexical Acquisition in Elementary Science Classes 48

Gross, J. and Teubal, E. (2001). Microscope use in scientific problem solving by kindergarteners.

Soil water seepage as an illustration, Proceedings of the 9th European Conference for

Research and Learning (EARLI), Fribourg-Switzerland, 28th Aug.-1st Sept. 2001.

Hargrave, A. C. \& Senechal, M. (2000). Book reading intervention with language-delayed preschool children: The benefits of regular reading and dialogic reading. Journal of Child Language, 15. 765-90.

Harlen, W. (2000). The teaching of science in primary schools ( $3^{\text {rd }}$ edition), London: David Fulton.

Hoff, E., \& Naigles, L. (2002). How children use input to acquire a lexicon. Child development, $73,418-433$.

Huttenlocher, J. (1974) The origins of language comprehension. In R. Solso (Ed.), Theories of cognitive psychology. Potomac MD: Erlbaum.

Klibanoff, S. R., \& Waxman, R. S. (2000). Basic level object categories support the acquisition of novel adjectives: evidence from preschool-aged children, Child Development, 71, 649659.

Kucera, H., \& Francis, W.N. (1967). Computational Analysis of Present-Day American English. Providence: Brown University Press.

Lemke, J. L. (1990). Talking Science: Language Learning and Values. Norwood, NJ: Ablex Publishing Corporation.

Lloyd, B., \& Contreras, N. (1987). Science inside-out. Science and Children, 25, 30-31.

McGregor, K., Friedman, R. M., Reilly, R. M., \& Newman, R. M. (2002). Naming representation and naming in young children' Journal of Speech, Language and Hearing Research, 45, 332346. 
Lexical Acquisition in Elementary Science Classes 49

McKeown, M. G., \& Beck, I. L. (2004). Direct and rich vocabulary instruction. In J. Baumann and E. Kame'enui (Eds.). Reading vocabulary: Research to practice, pp 13-27. New York, NY: Guilford Press.

McNeil, D. (1992). So you think gestures are nonverbal? Psychological Review, 92, 350-371.

Messer, D. J., \& Dockrell, J. E. (in press). What constitutes a word-finding problem? A Review Journal of Speech, Language and Hearing Research.

Mezynski, K. (1983). Issues concerning the acquisition of knowledge: Effects of vocabulary training and reading comprehension. Review of Educational Research, 53, 263-279.

Mintz, T., \& Gleitman, L. (2002). Adjectives really do modify nouns: The increment and restrictive nature of early adjective acquisition. Cognition, 84, 267-293.

Nagy, W. E., Diakidoy, I.-A., \& Anderson, R. C. (1993). The acquisition of morphology: learning the contribution of suffixes to the meanings of derivatives. Journal of Reading Behaviour, 25, 155-170.

Nagy, W., \& Herman, P. (1987). Depth and breadth of vocabulary knowledge: Implications for acquisition and instruction. In M. G. McKeown, \& Curtis M.E. (Eds.), The nature of vocabulary acquisition (pp. 19-35). Hillsdale, NJ. Erlbaum.

Naigles, L., \& Hoff-Ginesberg, E. (1995). Input to verb learning: evidence for the plausibility of syntactic bootstrapping. Developmental Psychology, 31, 827-837.

Nelson, K. (1988). “Constraints on word learning?” Cognitive Development, 3, 221-246.

Nelson, K. (1990). Comment on Behrend's "Constraints and development". Cognitive Development, 5, 331-339.

Nelson, K. (1996). Language in Cognitive Development: The Emergence of the Mediated Mind. Cambridge UK: Cambridge University Press.

Nippold, M. (1998). Later language development: the school age and adolescent years ( $2^{\text {nd }}$ ed.). Austin TX: Pro-Ed. 
Lexical Acquisition in Elementary Science Classes 50

Nippold, M. A., Cuyler, J. S., \& Braunbeck-Price, R. (1988). Explanation of ambiguous advertisements: a developmental study with children and adolescents. Journal of Speech and Hearing Research, 31, 466-474.

Ogborn, J., Kress, G., Martins, I., \& McGillicuddy, K. (1996). Explaining science in the classroom. Buckingham: Open University Press.

O’Toole, M. (1999). Language development through a practical approach to teaching science. Investigating, 15, 1, 19-22.

Oviatt, S. L. (1980). The emerging ability to comprehend language: An experimental approach. Child Development, 51, 97-106.

Penno, J. F., Wilkinson, A. G., \& Moore, D. S. (2002). Vocabulary acquisition from teacher explanation and repeated listening to stories: Do they overcome the Matthew effect? Journal of Educational Psychology, 94, (1), 23-33.

Prasada, S. (1997). Sentenial and non-sentenial cues to adjective meaning. Paper presented at the Biennial Meeting of the Society for Research in Child Development, Washington DC, $3^{\text {rd }}-6^{\text {th }}$ April.

Ralli, A. (1999). Investigating Lexical Acquisition Patterns: Context and Cognition. Unpublished PhD. Thesis, London: Institute of Education.

Ralli, A \& Dockrell, J. E. (in press 2005). Multiple measures of assessing vocabulary: Implications for understanding lexical development in Psychology, The Journal of the Hellenic Psychological Society, Ellinika, Grammata, 12, 587-603.-

Formatted: Font: $12 \mathrm{pt}$

Rennie, L. J., \& Jarvis, T. (1995). Children's choice of drawings to communicate their ideas about technology. Research in Science Education, 25, 239-252.

Robbins, C., \& Ehri, L. (1994). Reading storybooks to kindergarteners helps them learn new vocabulary words. Journal of Educational Psychology, 86, 56-64. 
Lexical Acquisition in Elementary Science Classes 51

Senechal, M. (1997). The differential effect of storybook reading on preschoolers' acquisition of expressive and receptive vocabulary. Child Language, 24, 123-138.

Senechal, M., Thomas, E., \& Monker, J.-A. (1995). Individual differences in 4-year-old children's acquisition of vocabulary during storybook reading. Journal of Educational Psychology, 87, 218-229.

Smiley, P., \& Huttenlocher, J. (1995). Conceptual Development and the Child's Early Words for Events, Objects, and Persons. In M. Tomasello \& W. Merriman (Eds.), Beyond Names for Things: Young Children's Acquisition of Verbs. Lawrence Erlbaum Associates.

Soler, V. (2002). Analysing adjectives in scientific discourse: an exploratory study with educational applications for Spanish speakers at advanced university level. English for Specific Purposes, 21, 145-165.

Stahl, S. and Fairbanks, M. (1986). The effects of vocabulary instruction: A model based on metaanalysis. Review of Educational Research, 56, 72-110.

Stanovich, K. E. (1995). Matthew effect in reading: Some consequences of individual differences in the acquisition of literacy. Reading Research Quarterly, 21, 360-407.

Thorndike, E.L., \& Lorge, I. (1944). The Teacher's Word Book of 30,000 Words. New York: Teachers College, Columbia University.

Tomasello. M. \& Akhtar, N. (1995). Two-year-olds use pragmatic cues to differentiate reference to objects and actions. Cognitive Development, 10, 201-224.

Waxman, S. R., \& Klibanoff, R. S. (2000). The role of comparison in the extension of novel adjectives, Developmental Psychology, 36, 571-581.

Wilson, M. (1998). Identifying and teaching essential science vocabulary. School Science Review, 80, 63-66. 
Lexical Acquisition in Elementary Science Classes 52

Table 1

Novel adjectives and familiar nouns

\begin{tabular}{llllll}
\hline Exposure & Entity set A & Entity set B & Control & Entity set A & Entity set B \\
Adjectives & & & adjectives & \\
Piebald & Flower & Mountain & Pallid & Leaf & River \\
Coarse & Tree & Sea & Translucent & River & Flower \\
Luminous & Sea & Leaf & & & \\
Verdant & Mountain & Tree & & & \\
\hline
\end{tabular}


Lexical Acquisition in Elementary Science Classes 53

Table 2

Proportion correct scores on the multiple-choice task

\begin{tabular}{llll}
\hline Time of testing & Combination & Synonym only & Control \\
& Mean (SD) & Mean (SD) & Mean (SD) \\
Baseline & $.11(.12)$ &.$\underline{19} z 0(.23)$ & $.114(.15)$ \\
Post-test & $.6 \underline{1} z(.33)$ & $.5 \underline{2} 7(.24)$ & $.18(.24)$ \\
& $.5 \underline{0} 7$ & $.3 \underline{3} 7$ & .04 \\
\hline
\end{tabular}

Note. Although the synonym only children performed better than combination only children and control children at baseline there was no significant effect of group, $F=1.6, p=.21$. 
Lexical Acquisition in Elementary Science Classes 54

Table 3

Proportion of correct scores on the picture-naming, definition and drawing tasks

\begin{tabular}{llll}
\hline Task & Combination & Synonym only & Control \\
& Mean (SD) & Mean (SD) & Mean (SD) \\
Picture-naming & $.12(.19)$ & $.02(.02)$ & 0 \\
Drawing & $.2 \underline{3} 5(.30)$ & $.0 \underline{9} 7(.14)$ & 0 \\
Definition &.$\underline{29} 31(.30)$ & $.1 \underline{4} z(.15)$ & 0 \\
\hline
\end{tabular}


Lexical Acquisition in Elementary Science Classes 55

Table 4

Correlations between correct responses on the immediate post-test tasks

\begin{tabular}{lllll}
\hline Tasks & Picture naming & Multiple-choice & Drawing & Definition \\
Picture-naming & ------ & & \\
Multiple-choice & .35 & ------ & \\
Drawing & $.51 *$ & $.47^{*}$ & ------ & \\
Definition & $.54 *$ & $.40 *$ & $.86^{* *}$ & ----- \\
\hline
\end{tabular}

Note: $*=\mathrm{p}<0.05 ; * *=\mathrm{p}<0.01$ 
Lexical Acquisition in Elementary Science Classes 56

Appendix

\section{Exposure Script 1}

Today we are going to think about things we see outside. Things we see in the country or at the seaside. I am going to show you some pictures. I want you to look for things that alive and growing, and things that are not alive.

Item 1: Piebald. What can you see in this picture? What is alive? What is growing? What isn't alive?

So this is a house [points to image of a house when the word "this" is used] and this is a tree [points to image of a tree when the word "this" is used].

This is a piebald flower [points to image of a flower when the word "this" is used].

Item 2: Coarse. What can you see in this picture? What is alive? What is growing? What isn't alive?

So, this is a river [points to image of a river when the word "this" is used] and this is a hill [points to image of a hill when the word "this" is used].

This is a coarse tree [points to image of a tree when the word "this" is used].

Item 3: Luminous. What can you see in this picture? What is alive? What is growing? What isn't alive?

So this is a tree [points to image of a tree when the word "this" is used] and this is a mountain [points to image of a mountain when the word "this" is used].

This is a luminous sea [points to image of the sea when the word "this" is used].

Item 4: Verdant. What can you see in this picture? What is alive? What is growing? What isn't alive?

So this is the sea [points to image of the sea when the word "this" is used] and this is a tree [points to image of a tree when the word "this" is used].

This is a verdant mountain [points to image of a tree when the word "this" is used]. 


\section{Lexical Acquisition in Elementary Science Classes 57}

We've seen all the pictures now. We have seen mountains, trees, flowers and rivers.

Now, I am going to work with you one at a time. While you are waiting for your turn I would like you to go back to your table and carry on with your work. 
Lexical Acquisition in Elementary Science Classes 58

\section{Exposure Script 2}

Today we are going to think about flowers. I am going to show you some flowers. I want you to tell me about them.

Item 1: Piebald. Let's have a look at the first flower [pointing to flower].

I would like you all to tell me something about the flower [show flower to each child in the group and ask the child to make a comment].

If you look, you can see that it is a piebald flower. Piebald means spotted [Circling finger over petals, emphasising spots (while speaking). Experimenter moves flower toward each child in the group].

Item 2: Coarse. Let's have a look at the next flower [pointing to flower].

I would like you all to tell me something about the flower [show flower to each child in the group and ask the child to make a comment].

If you look, you can see that it is a coarse flower. Coarse means bumpy [Moving fingers over rough pats of leaves, next to petals, emphasising that the texture is bumpy (while speaking). Experimenter moves flower toward each child in the group].

Item 3: Luminous. Let's have a look at the next flower [pointing to flower]. I would like you all to tell me something about the flower [show flower to each child in the group and ask the child to make a comment].

If you look, you can see that it is a luminous flower. Luminous means shiny [Stroking petals, emphasising shininess (while speaking). Experimenter moves flower toward each child in the group].

Item 4: Verdant. Let's have a look at the last flower [pointing to flower]. I would like you all to tell me something about the flower [show flower to each child in the group and ask the child to make a comment]. 
Lexical Acquisition in Elementary Science Classes 59

If you look, you can see that it is a verdant flower. Verdant means green [Moving hands over petals, emphasising the green colour (while speaking). Experimenter moves flower toward each child in the group].

Now we have looked at the flowers, I am going to work with you one at a time. While you are waiting for your turn I would like you to go back to your table and carry on with your work. 